\title{
Four new species of the genus Carinostigmus Tsuneki (Hymenoptera, Apoidea, Crabronidae) from Oriental China, with an updated key to the Chinese species
}

\author{
Nawaz Haider Bashir', Qiang Li', Li Ma' \\ I Department of Entomology, College of Plant Protection, Yunnan Agricultural University, Kunming, Yunnan, \\ 650201, China \\ Corresponding author: Qiang Li (liqiangkm@126.com); Li Ma (maliwasps@aliyun.com) \\ Academic editor: Michael Ohl | Received 10 December 2020 | Accepted 8 February 2021 | Published 25 February 2021 \\ http://zoobank.org/6983B007-E436-4C51-B938-D2C00685139F \\ Citation: Bashir NH, Li Q, Ma L (2021) Four new species of the genus Carinostigmus Tsuneki (Hymenoptera, \\ Apoidea, Crabronidae) from Oriental China, with an updated key to the Chinese species. Journal of Hymenoptera \\ Research 81: 87-107. https://doi.org/10.3897/jhr.81.61892
}

\begin{abstract}
The taxonomy of the apoid wasps of the genus Carinostigmus from China is studied, with description of four new species, namely Carinostigmus capiconvergens Bashir \& Ma, sp. nov., Carinostigmus longivertex Bashir \& Ma, sp. nov., Carinostigmus rugipunctatus Bashir \& Ma, sp. nov., and Carinostigmus triangularis Bashir \& Ma, sp. nov. An updated key to the Chinese species of Carinostigmus is provided.
\end{abstract}

\section{Keywords}

Apoid wasps, identification key, Oriental region, Stigmina, taxonomy

\section{Introduction}

Carinostigmus was described by Tsuneki (1954) as subgenus of Stigmus Panzer, 1804, and was elevated to genus level by Bohart and Menke (1976). Carinostigmus belongs to the subfamily Pemphredoninae and currently comprises of 40 species and one subspecies worldwide. A huge diversity is found in the Oriental region with 23 species, followed by Afrotropical realm with 11 species and one subspecies; two species in this diversity are distributed across Palearctic region and four species are both Palearctic and 
Oriental regions (Maidl 1925; Gussakovskij 1934; Tsuneki 1954, 1956, 1966, 1974, 1976, 1977; Bohart and Menke 1976; Krombein 1984; Bashir et al. 2020; Pulawski 2020; Rajan et al. 2020). To date, 13 species have been reported from China (Fig. 1), out of which 10 species are present in Oriental China, and 3 species are found in both Oriental and Palearctic China (Li and Yang 1995; Li and He 2004; Ma et al. 2012, 2018). Recently, three new species of Carinostigmus: C. frontirugatus Bashir \& Ma, C. latidentatus Bashir \& Ma, and C. vesulcatus Bashir \& Ma and one new record C. palawanensis (Tsuneki) have been described from the Oriental region of China (Bashir et al. 2020).

The current study described four new species of Carinostigmus from China as: C. capiconvergens sp. nov., C. longivertex sp. nov., C. rugipunctatus sp. nov., and C. triangularis sp. nov. The key by Bashir et al. (2020) to the Chinese species of Carinostigmus is updated.

\section{Materials and methods}

Institutional abbreviations:

YNAU Insect Collections of Yunnan Agricultural University, Kunming, Yunnan, China; ZJU Parasitic Hymenoptera Collection of Zhejiang University, Hangzhou, Zhejiang Province, China.

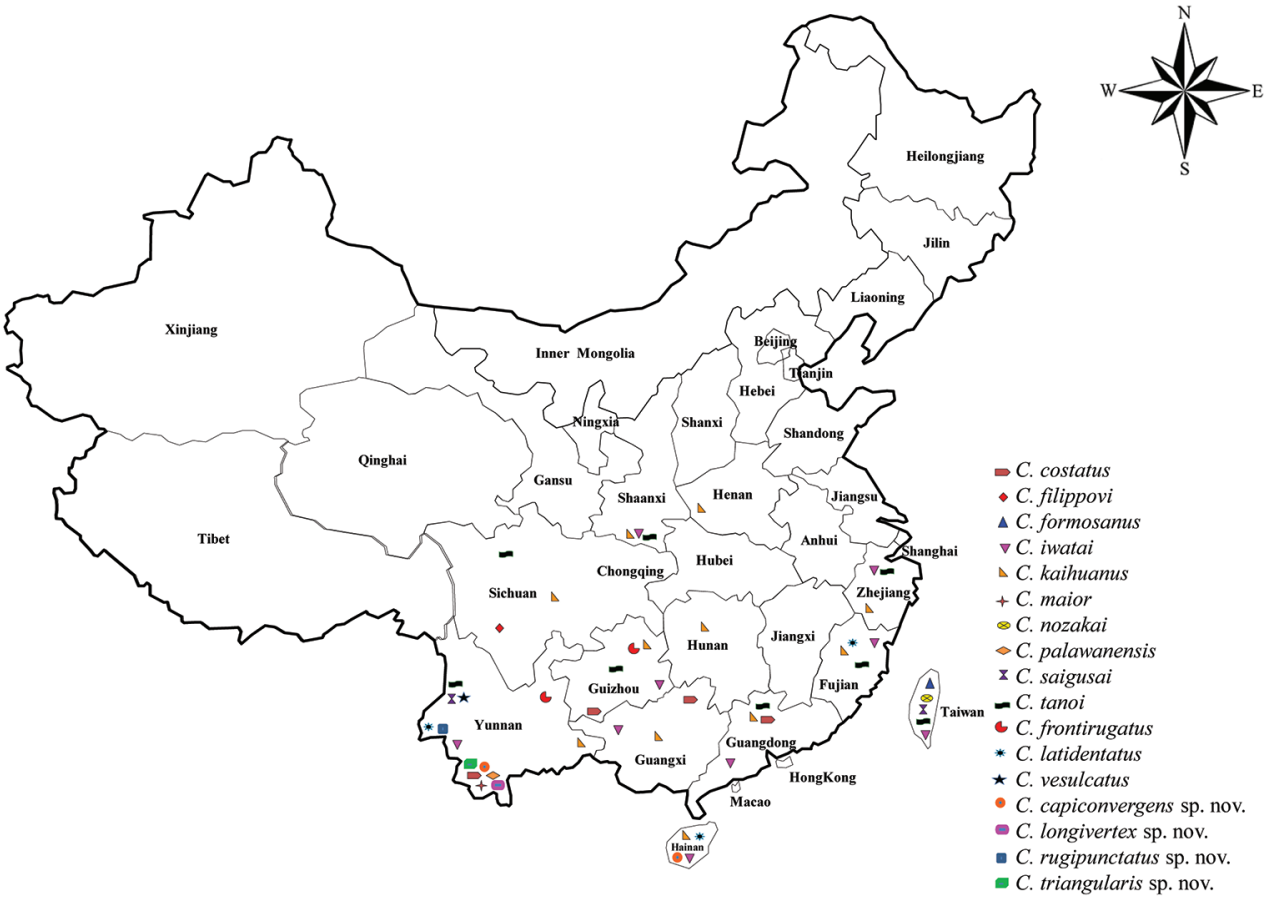

Figure I. Map showing records of Carinostigmus from China (updated from Bashir et al. 2020). 
Specimens were examined with an Olympus stereomicroscope (SZ Series) with an ocular micrometer. The images were taken with a Keyence VHX-5000 digital optical microscope (camera with resolution of $1600 \times 1200$ pixels), and edited with Adobe Photoshop 8.0. Measurements and ratio were acquired using an ocular scale on Olympus stereo microscope SZX2-TR30 at $2 \times$ and $5.4 \times$ magnification, respectively.

For terminology, we mainly followed Bohart and Menke (1976), Harris (1979), and Bashir et al. (2020). The descriptions are based on the holotypes only, and paratypes displaying some variation are given in square brackets in detail.

\section{Taxonomy}

\section{Genus Carinostigmus Tsuneki, 1954}

Type species. Stigmus congruus Walker, 1860; by original designation.

\section{Carinostigmus capiconvergens Bashir \& Ma, sp. nov.} http://zoobank.org/47816309-3CC6-4422-9AA0-859DEFE1FAF6 Figs 2, 6A, B

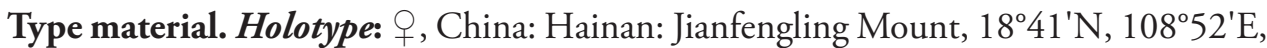
6.VI.2007, 900-950 m, No. 200707957, coll. Jingxian Liu (ZJU). Paratypes: 1우, same locality as holotype, 7.VI.2007, No. 200707997; 1§, same locality and date as holotype, No. 200707955; 1 , China: Yunnan: Jinghong: Menghai: Bulang Mountain, $21^{\circ} 56^{\prime}$ N, $100^{\circ} 26^{\prime} E, 2018 . I V .24-V .17$, No. 2019000007, coll. Malaise trap (YNAU).

Diagnosis. This new species can be separated from all other Carinostigmus species from China by the following character combinations: free margin of clypeus emarginate; median and lower frons with broad frontal median furrow; upper frons without longitudinal carina; occipital carina broad, distinctly foveolate; admedian line extending to half of scutum length; mesopleuron with longitudinal rugae posteriorly; propodeum with large smooth area medially. It is closely related to C. iwatai (Tsune$\mathrm{ki}, 1954$ ), but differs from it in the following characters (characters of C. iwatai in brackets): inter-antennal tubercle short, less than midocellus diameter (inter-antennal tubercle long, more than midocellus diameter); ocellar triangle and vertex behind ocelli impunctate (ocellar triangle and vertex behind ocelli finely punctate); occipital carina broad as Fig. 2B, distinctly foveolate (occipital carina narrow as Fig. 3B, without foveolate); outer and inner orbital furrows narrow as Fig. 2A (outer and inner orbital furrows broad as Fig. 3A); pronotal collar without rugae (pronotal collar with sparse and sturdy rugae); scutum with transverse striations anteriorly (scutum without striations); parapsidal and admedian lines inconspicuous (parapsidal and admedian lines distinct); metanotum with dense, slender longitudinal rugae medially (metanotum without rugae medially); omaulus broad, $1.3 \times$ pedicel width (omaulus 

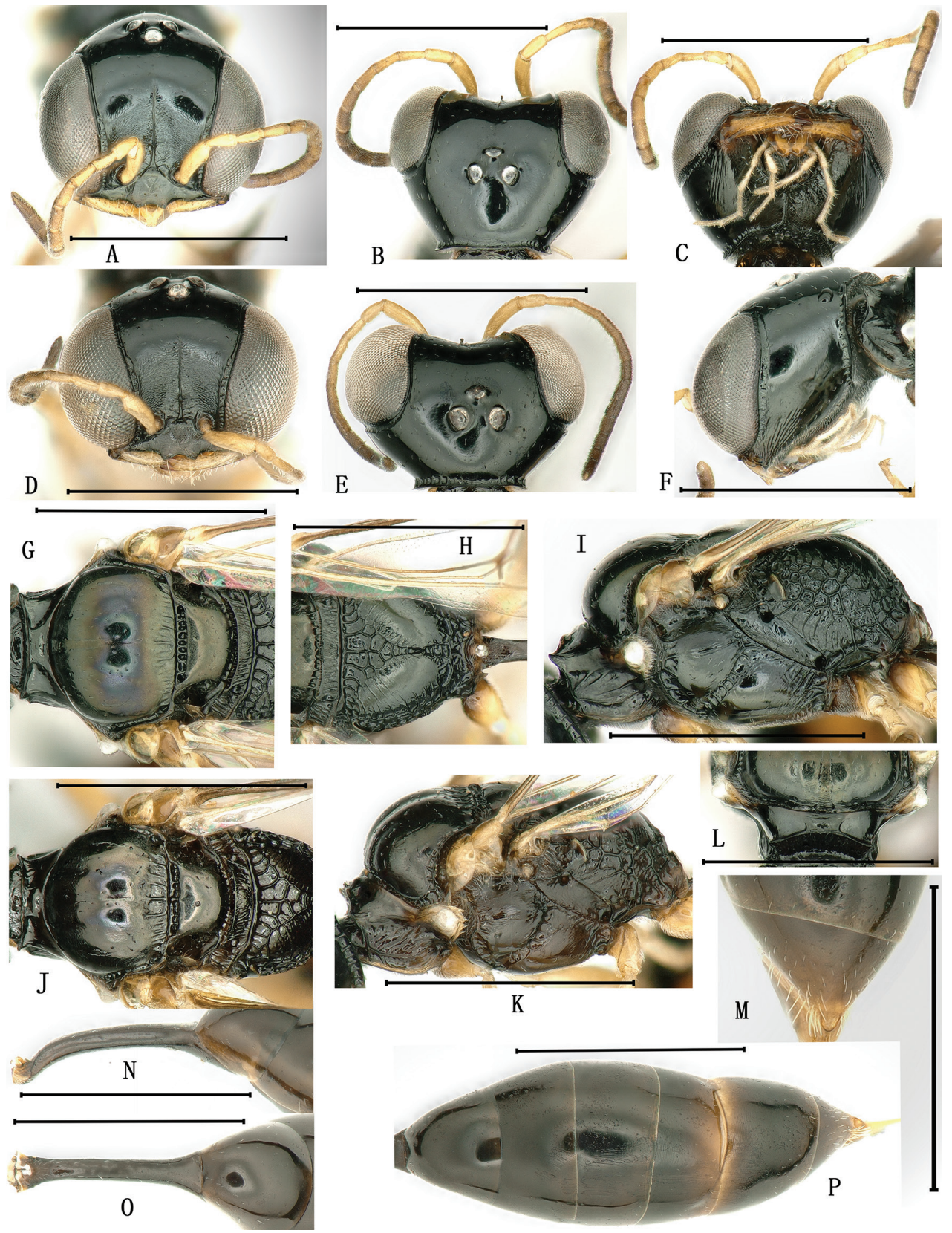

Figure 2. Carinostigmus capiconvergens Bashir \& Ma, sp. nov. (A-C, F-I, L-P female D, E, J, K male) $\mathbf{A}, \mathbf{D}$ head, frontal $\mathbf{B}, \mathbf{E}$ head, dorsal $\mathbf{C}$ head, ventral $\mathbf{F}$ head, lateral $\mathbf{G}, \mathbf{J}$ scutum, scutellum and metanotum, dorsal $\mathbf{H}$ propodeum, dorso-posterior $\mathbf{I}, \mathbf{K}$ thorax, lateral $\mathbf{L}$ scutum anterior, dorsal $\mathbf{M}$ pygidial plate $\mathbf{N}$ petiole, lateral $\mathbf{O}$ petiole, dorsal $\mathbf{P}$ metasoma, dorsal. Scale bars: $1.0 \mathrm{~mm}$.

narrow, $0.8 \times$ pedicel width); scrobal suture lacking (scrobal suture present, short as Fig. 4I); propodeum posterior with large smooth area medially (propodeum posterior with small smooth area medially); petiole laterally smooth (petiole laterally with few 
weak carinae) and pygidial area smooth, u-shaped (pygidial area punctate medially, oval shaped).

Description. Female (Figs 2A-C, F-I, L-P, 6A): length of body 4.9 [4.5-5.0] mm.

Colouration. Body black and shiny, except for the following: mandible (reddish brown apically), labrum, scape, pedicel, flagellomeres I-IV (remainder reddish brown to dark brown), tegula, fore and mid femur extensively (remainder ivory to yellowish), hindleg (basal one third to half of tibia ivory, remainder dark brown) fulvous; palpi and pronotal lobe ivory; forewing veins dark brown; setae on mandible and margin of clypeus golden.

Head (Fig. 2A-C, F). Mandible tridentate apically; labrum pentagonal, gently round toward apex; clypeus nearly flat, with several coarse punctures medially; free margin of median lobe of clypeus narrowly produced, nearly truncate, with two small lateral teeth, lateral lobe with inconspicuous tooth (Fig. 2A); setae on margin of clypeus and mandible long, longer than labrum length; median and lower frons coriaceous, dull, with broad, deep frontal median furrow, a sturdy frontal median longitudinal carina, inter-antennal tubercle shorter than midocellus diameter; upper frons with several fine punctures, longitudinal carina lacking (Fig. 2A); ocellar triangle area impunctate, nearly flat; vertex behind ocelli impunctate (Fig. 2B); gena with several slender oblique transverse rugae near mandible area (Fig. 2F); lower gena with fine, sparse punctures medially (Fig. 2C); occipital carina broad, distinctly foveolate (Fig. 2B); inner orbital furrow narrow, with inner marginal carina distinct, coarsely foveolate (Fig. 2A); outer orbital furrow narrow, hind marginal carina slender, inconspicuously foveolate (Fig. 2F); length of scape: length of pedicel: length of flagellomere I: width of flagellomere $I=20: 8: 8: 3$; maximum head width, dorsally: distance from upper margin of the frons to occipital carina in middle: distance from vertex to clypeal margin in middle $=64: 39: 51$; maximum eye length, laterally: maximum eye width, laterally: maximum eye width, frontal view $=40: 22: 18$; inner-orbital width, medially: outerorbital width, medially: occipital carina width, dorsally $=2: 2: 2$; maximum width of gena, laterally: distance between antennal sockets, frontal view $=16: 10$; distance between inner margins of hind ocelli: distance between outer margin of hind ocellus and nearest inner eye margin: distance between posterior margin of hind ocellus and occipital carina, dorsally $=6: 13: 17$.

Mesosoma (Fig. 2G-I, L). Pronotal collar smooth, slightly elevated medially, anterior pronotal ridge strong, lateral angles projected and sharp; width of collar in middle: length of collar in middle $=5: 30$; mesoscutum with coarse, sparse punctures, several slender, transverse striations anteriorly (Fig. $2 \mathrm{~L}$ ), posterior area with sparse, strong, parallel ridges (Fig. 2G); admedian line inconspicuous, extending to nearly half of scutum length; notaulus inconspicuous [invisible], extending to anterior $1 / 4$ of scutum length; parapsidal line weakly impressed; scutellum with fine, sparse punctures; metanotum with dense, slender, longitudinal rugae (Fig. 2G); mesopleuron with several sturdy, short, longitudinal rugae posteriorly, hypoepimeral area with few slender, longitudinal rugae; omaulus and hypersternaulus broad, $1.3 \times$ pedicel width, distinctly foveolate, scrobal suture lacking (Fig. 2I); propodeal enclosure shallowly impressed, triangular, with sturdy longitudinal rugae, median area reticulate; propodeum posterior with broad median groove, several fairly slender, oblique, longitudinal rugae anteriorly 
[inconspicuously], large smooth area medially, and irregular reticulation posteriorly (Fig. $2 \mathrm{H}$ ); propodeum laterally with several slender, oblique, longitudinal rugae anteriorly, and irregular, reticulation posteriorly (Fig. 2I).

Metasoma (Fig. 2M-P). Petiole dorsal nearly cylindrical, slightly convex, basal width equal as apical width (Fig. 2O), petiole laterally smooth (Fig. $2 \mathrm{~N}$ ); maximum width of petiole, dorsally: length of petiole, laterally: maximum length of metasomal tergum I, dorsally: maximum width of metasomal tergum I, dorsally $=6: 47: 30: 32$; metasomal sterna IV-VI with dense, fine punctures, remaining sterna nearly impunctate (Fig. 2P); pygidial area smooth, depressed, u-shaped, apex truncate (Fig. 2M).

Male (Figs 2D, E, J, K, 6B). Similar to female except length of body $4.5 \mathrm{~mm}$; mandible ivory (reddish brown apically); setae on mandible and margin of clypeus yellowish; mandible bidentate apically; clypeus slightly convex; setae on mandible short, less than labrum length; lower gena with irregular, rugulose medially; outer orbital furrow with hind marginal carina foveolate; length of scape: length of pedicel: length of flagellomere I: width of flagellomere $\mathrm{I}=17: 6: 7: 2$; maximum head width, dorsally: distance from upper margin of the frons to occipital carina in middle: distance from vertex to clypeal margin in middle $=60: 33: 45$; maximum eye length, laterally: maximum eye width, laterally: maximum eye width, frontal view $=35: 20: 19$; maximum width of gena, laterally: distance between antennal sockets, frontal view $=14$ : 7; distance between inner margins of hind ocelli: distance between outer margin of hind ocellus and nearest inner eye margin: distance between posterior margin of hind ocellus and occipital carina, dorsally = 5: 11: 14; width of collar in middle: length of collar in middle $=5: 24$; maximum width of petiole, dorsally: length of petiole, laterally: maximum length of metasomal tergum I, dorsally: maximum width of metasomal tergum I, dorsally $=5: 45: 25: 25$; sterna III-VI with sparse, fine punctures.

Distribution. China (Hainan, Yunnan).

Etymology. The name, capiconvergens, is derived from the Latin words caput (= head) and con-vergo (= converge), referring to the head from above with temples distinctly convergent posteriorly.

\section{Carinostigmus longivertex Bashir \& Ma, sp. nov.}

http://zoobank.org/D5C82AC9-573C-4865-91C5-2D392A3E6EDA

Figs 3, 6C

Type material. Holotype: $q$, China: Yunnan: Mengla: Wangtianshu Forest Park, $21^{\circ} 34^{\prime} \mathrm{N}, 101^{\circ} 39^{\prime} \mathrm{E}, 1 . \mathrm{V} .2005$, coll. Peng Wang (YNAU). Paratypes: 2 , same data as holotype; 1 , , China: Yunnan: Dehong: Nabang, $24^{\circ} 26^{\prime} \mathrm{N}, 98^{\circ} 35^{\prime} \mathrm{E}, 15 . \mathrm{V} .2009$, No. 201005193, coll. Jie Zeng (YNAU).

Diagnosis. Within Chinese Carinostigmus, this new species can be separated by the following character combinations: free margin of clypeus conspicuously produced, slightly emarginated in middle; median and lower frons with shallow frontal median furrow; inter-antennal tubercle distinctly broadened at apex; vertex behind ocelli finely punctate; lower gena coarsely punctate; occipital carina without foveolate; anterior 


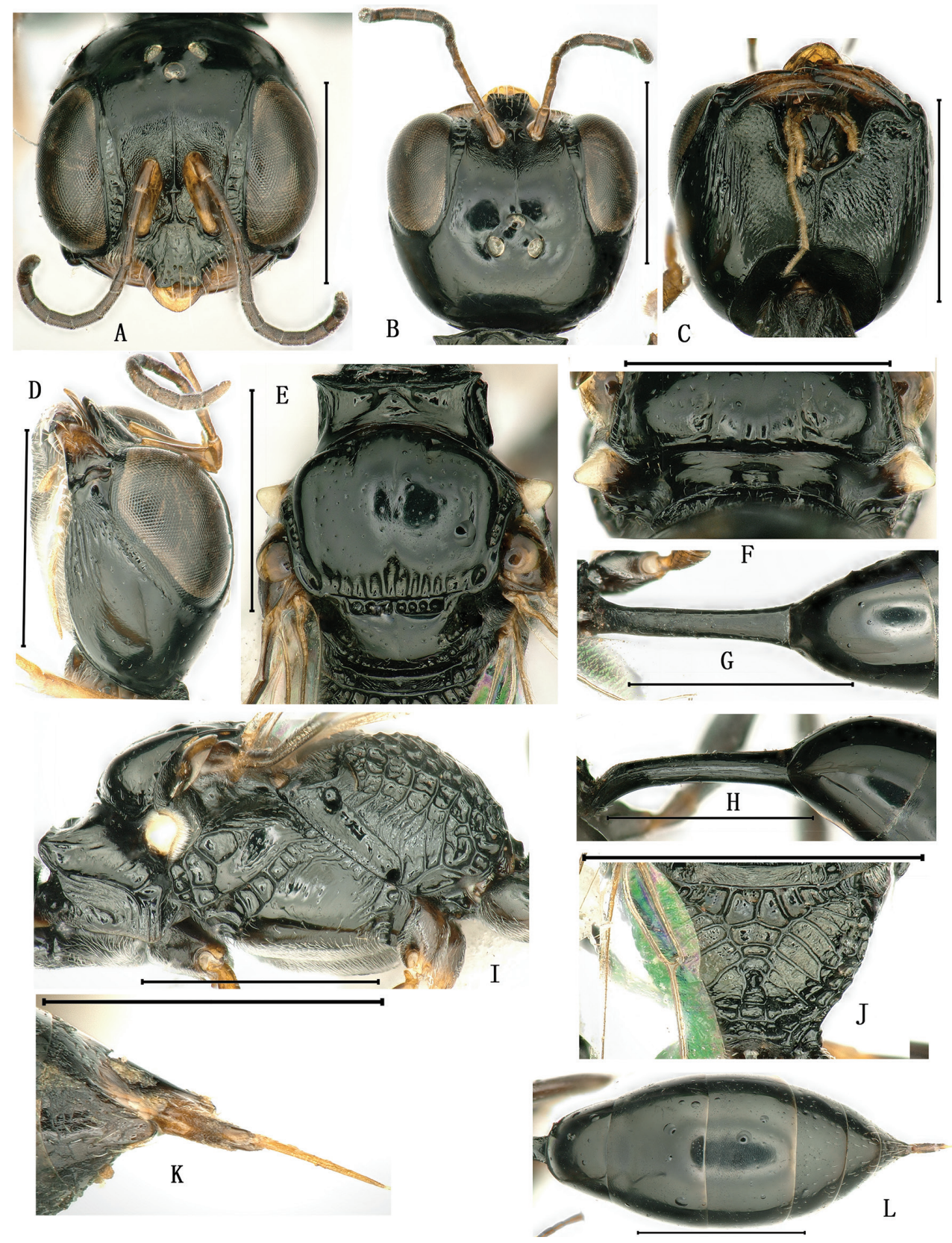

Figure 3. Carinostigmus longivertex Bashir \& Ma, sp. nov. (female) A head, frontal $\mathbf{B}$ head, dorsal $\mathbf{C}$ head, ventral D head, lateral $\mathbf{E}$ scutum, scutellum and metanotum, dorsal $\mathbf{F}$ scutum anterior, dorsal $\mathbf{G}$ petiole, dorsal $\mathbf{H}$ petiole, lateral $\mathbf{I}$ thorax, lateral $\mathbf{J}$ propodeum, dorso-posterior $\mathbf{K}$ pygidial plate $\mathbf{L}$ metasoma, dorsal. Scale bars: $1.0 \mathrm{~mm}$.

pronotal ridge narrowly emarginate in middle; scutellum median line impressed; propodeum with small smooth area medially; basal half of petiole with transverse striations; petiole laterally carinate. Carinostigmus longivertex sp. nov. resembles $C$. iwatai 
(Tsuneki) 1954, but can be distinguished from it by the following characters (characters of $C$. iwatai in brackets): free margin of clypeus emarginated medially (free margin of clypeus truncate medially); inter-antennal tubercle distinctly broadened at apex as Fig. 3B (inter-antennal tubercle not broad as Fig. 4B); lower gena with coarse, dense punctures mixed with dense, irregular, longitudinal rugae medially (lower gena with fine, sparsed punctured, without rugae); outer orbital furrow narrow as Fig. 3D (outer orbital furrow broad); admedian and parapsidal lines inconspicuous (admedian and parapsidal lines distinct); notaulus deeply grooved (notaulus shallowly grooved); metanotum median area with dense, slender, transverse rugae (metanotum without rugae); omaulus broad, $1.2 \times$ pedicel width (omaulus narrow, $0.8 \times$ pedicel width); basal half of petiole with dense, slender, irregular transverse striations dorsally (petiole without striations) and pygidial area u-shaped (pygidial area oval shaped).

Description. Female (Figs 3, 6C): length of body 6 [5.7-6.1] mm.

Colouration. Body black and shiny, except for the following: mandible (black basally and apically) and labrum reddish brown; palpi, scape and pedicel fulvous; flagellomeres reddish brown to dark brown; pronotal lobe ivory; tegula and forewing veins dark brown; fore trochanter, base and apex of femur, tibia, tarsi fulvous to reddish brown (remainder dark brown to black); mid trochanter, base and apex of femur, tibia extensively, tarsi fulvous; hind trochanter reddish brown, tibia and tarsus dark brown; setae on mandible and margin of clypeus yellowish.

Head (Fig. 3A-D). Mandible tridentate apically; labrum pentagonal, gently round toward apex; clypeus moderately convex, with sparse, coarse punctures; free margin of clypeus conspicuously produced with two distinctly triangular teeth, slightly emarginated in middle (Fig. 3A); setae on mandible and margin of clypeus long, more than labrum length; median and lower frons coriaceous, with broad, shallow frontal median furrow, a strong frontal median longitudinal carina, inter-antennal tubercle distinctly broadened at apex, long, more than midocellus diameter; upper frons with sparse, fine punctures, longitudinal carina distinct anteriorly, not reaching anterior ocellus (Fig. 3A); ocellar triangle area nearly flat, finely punctate; vertex behind ocelli with fine punctures (Fig. 3B); gena with sparse, coarse punctures and several sturdy, long, oblique transverse rugae (Fig. 3D); lower gena with coarse, dense punctures mixed with dense, irregular, longitudinal rugae medially [weakly] (Fig. 3C); occipital carina narrow, without foveolate (Fig. 3B); inner orbital furrow broad as $0.8 \times$ pedicel length, with inner marginal carina distinct, coarsely foveolate (Fig. 3A); outer orbital furrow narrow as $0.5 \times$ pedicel length, hind marginal carina inconspicuous, finely foveolate (Fig. 3D); length of scape: length of pedicel: length of flagellomere I: width of flagellomere $\mathrm{I}=26$ : 10: 11: 3; maximum head width, dorsally: distance from upper margin of the frons to occipital carina in middle: distance from vertex to clypeal margin in middle $=82: 57: 65$; maximum eye length, laterally: maximum eye width, laterally: maximum eye width, frontal view $=51: 30: 19$; inner-orbital width, medially: outerorbital width, medially: occipital carina width, dorsally $=5: 3: 1$; maximum width of gena, laterally: distance between antennal sockets, frontal view $=28: 15$; distance between inner margins of hind ocelli: distance between outer margin of hind ocellus 
and nearest inner eye margin: distance between posterior margin of hind ocellus and occipital carina, dorsally $=7: 16: 29$.

Mesosoma (Fig. 3E, F, I, J). Pronotal collar strongly elevated medially, triangular, with several inconspicuous rugae laterally, anterior pronotal ridge strong, narrowly emarginate in middle, lateral angles strong and distinctly projected (Fig. 3E); width of collar in middle: length of collar in middle $=9: 45$; mesoscutum with coarse, sparse punctures, anterior without striations (Fig. $3 \mathrm{~F}$ ), posterior area with several strong parallel ridges, longer in middle than laterally (Fig. 3E); admedian line inconspicuous [sometimes visible], extending to half of scutum length; notaulus deeply grooved, extending to anterior $1 / 4$ of scutum length (Fig. 3F); parapsidal line weakly impressed; scutellum with fine, sparse punctures, median line impressed; metanotum with several sturdy, longitudinal rugae on lateral area, median area with dense, slender, transverse rugae (Fig. 3E); mesopleuron with coarse, sparse punctures, hypoepimeral and posterior area with slender or sturdy, dense, long longitudinal rugae posteriorly; scrobal suture, omaulus and hypersternaulus broad and distinct, foveolate, scrobal suture short, incomplete (Fig. 3I); propodeal enclosure moderately impressed, triangular, with sturdy longitudinal rugae, median area reticulate; propodeum posterior with broad shallow median groove, sparse, sturdy, oblique longitudinal rugae anteriorly, small smooth area medially, and irregular reticulation posteriorly (Fig. 3J); propodeum laterally with dense or sparse sturdy, oblique, longitudinal rugae anteriorly, and irregular, reticulation posteriorly (Fig. 3I).

Metasoma (Fig. 3G, H, K, L). Petiole dorsal nearly cylindrical, slightly convex and widened toward apex slightly, basal half of petiole with dense, slender, irregular transverse striations (Fig. 3G), petiole laterally with few weak carinae (Fig. 3H); maximum width of petiole, dorsally: length of petiole, laterally: maximum length of metasomal tergum I, dorsally: maximum width of metasomal tergum I, dorsally = 8: 60: 37: 42; metasomal sterna IV-VI with fine, dense punctures, remainder nearly impunctate (Fig. 3L); pygidial area coriaceous, depressed, u-shaped, apex truncate (Fig. 3K).

Male. Unknown.

Distribution. China (Yunnan).

Etymology. The name, longivertex, is derived from the Latin words longus (= long) and vertex (= vertex), referring to the very long vertex, with the ocello-occipital distance (OCD) being four times as long as postocellar distance (POD), 29 : 7. A noun in apposition.

\section{Carinostigmus rugipunctatus Bashir \& Ma, sp. nov.}

http://zoobank.org/6C5145C9-D153-4163-9878-7C9B24886E0A

Figs 4, 6D, E

Type material. Holotype: $q$, China: Yunnan: Jinghong: Xishuangbanna National Forest Park, $22^{\circ} 01^{\prime} \mathrm{N}, 100^{\circ} 52^{\prime} \mathrm{E}, 31$. VII.2003, 600-1000 m, coll. Qiang Li (YNAU). Paratypes: $698 \bigcirc^{\lambda}$, same locality and date as holotype, coll. Tingjing Li, Peng Wang (ZJU);

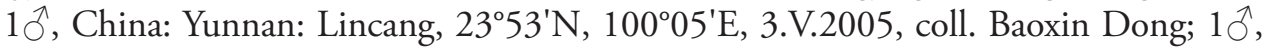
China: Yunnan: Ruili, $24^{\circ} 01^{\prime} \mathrm{N}, 97^{\circ} 51^{\prime} \mathrm{E}, 29 . \mathrm{IV} .1981$, coll. Junhua He (YNAU). 


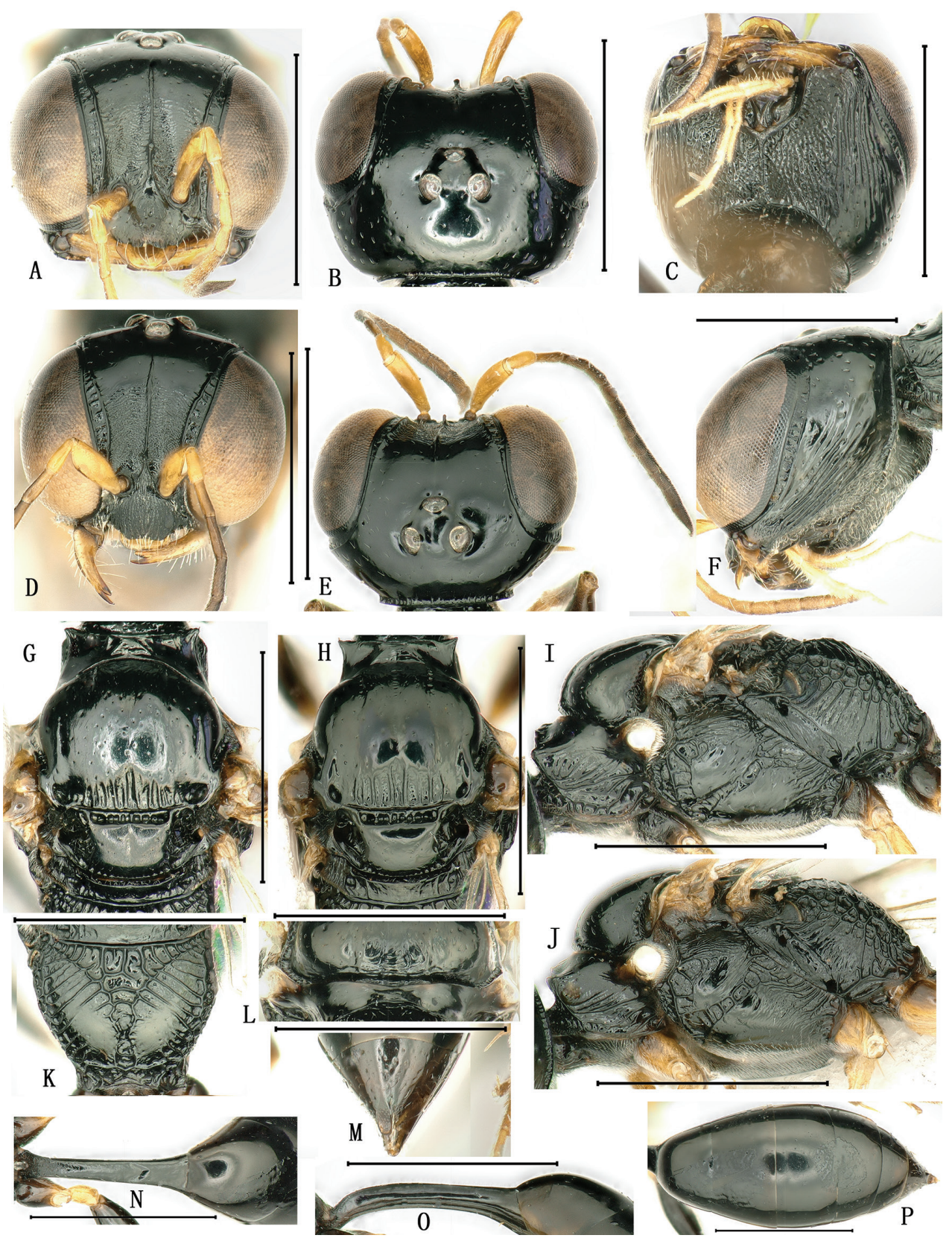

Figure 4. Carinostigmus rugipunctatus Bashir \& Ma, sp. nov. (A-C, F, G, I, K-P female $\mathbf{D}, \mathbf{E}, \mathbf{H}, \mathbf{J}$ male) A, D head, frontal B, E head, dorsal $\mathbf{C}$ head, ventral $\mathbf{F}$ head, lateral $\mathbf{G}, \mathbf{H}$ scutum, scutellum and metanotum, dorsal $\mathbf{I}$, J thorax, lateral $\mathbf{K}$ propodeum, dorso-posterior $\mathbf{L}$ scutum anterior, dorsal $\mathbf{M}$ pygidial plate $\mathbf{N}$ petiole, dorsal $\mathbf{O}$ petiole, lateral $\mathbf{P}$ metasoma, dorsal. Scale bars: $1.0 \mathrm{~mm}$.

Diagnosis. This new species can be separated from all other Carinostigmus species from China by the following character combinations: mandible reddish brown basally; legs largely fulvous; labrum truncate apically; free margin of median lobe of clypeus 
broadly produced; median frons rugulose; occipital carina broad, without foveolate; lateral angles of pronotal collar not projected; metanotum smooth medially; propodeum with large smooth area medially; petiole dorsal with irregularly weak rugae basally; pygidial area depressed. It is closely related to C. congruus (Walker) 1860, but differs from it in the following characters (states of $C$. congruus in brackets): inter-antennal tubercle without T-shape at apex (inter-antennal tubercle with T-shaped at apex); inner orbital furrow inconspicuously foveolate (inner orbital furrow distinctly foveolate); pronotal ridge strongly marked (pronotal ridge weakly marked), slightly emarginate in middle (not emarginate in middle); occipital carina broad as Fig. 4B (occipital carina narrow as Fig. 3B); lower gena with dense, sturdy, longitudinal rugae medially (lower gena without rugae medially); notaulus inconspicuously grooved, extending to one third of scutum length (notaulus strongly impressed, extending to anterior $1 / 4$ of scutum length); propodeum with smaller smooth area than $C$. congruus; petiole dorsal with few irregularly weak rugae basally (petiole dorsal without rugae); petiole laterally smooth (petiole laterally with a few weak carinae or smooth) and pygidial area u-shaped (pygidial area oval shaped).

Description. Female (Figs 4A-C, F, G, I, K-P, 6D): length of body 5.4 [5.2-5.5] mm.

Colouration. Body black and shiny, except for the following: mandible (reddish brown basally and apically), labrum, palpi, scape, pedicel, flagellomere I-III (remainder dark brown) and tegula fulvous; pronotal lobe ivory; forewing veins dark brown; fore trochanter, base and apex of femur, tibia, tarsi yellowish to fulvous (remainder dark brown); mid trochanter, base and apex of femur, tibia extensively, tarsi fulvous (remainder dark brown); hind trochanter, basal one third of tibia fulvous (remainder dark brown); setae on mandible and margin of clypeus golden.

Head (Fig. 4A-C, F). Mandible tridentate apically; labrum pentagonal, truncate apically; clypeus moderately convex, with sparse, fine mixed with coarse punctures; free margin of median lobe of clypeus broadly produced and emarginate apically, with four teeth, median teeth distinct, subquadrate, slightly turnup, lateral teeth small, inconspicuous [sometimes lacking] (Fig. 4A); setae on mandible and margin of clypeus sparse, long, more than labrum length; median and lower frons coriaceous, rugulose on median frons, with broad, shallow frontal median furrow, a sturdy frontal median longitudinal carina, inter-antennal tubercle short, less than midocellus diameter; upper frons with sparse, fine punctures, longitudinal carina distinct anteriorly, not reaching anterior ocellus (Fig. 4A); ocellar triangle area slightly convex, several finely punctate; vertex behind ocelli with sparsely finely punctate (Fig. 4B); gena with dense, slender, long, oblique transverse rugae (Fig. 4F); lower gena with coarse, dense punctures mixed with dense, sturdy, longitudinal rugae medially (Fig. 4C); occipital carina broad, without foveolate (Fig. 4B); inner orbital furrow broad, with inner marginal carina distinct, inconspicuously foveolate (Fig. 4A); outer orbital furrow narrow, hind marginal carina distinct, finely foveolate (Fig. 4F); length of scape: length of pedicel: length of flagellomere I: width of flagellomere I = 21: 7: 9: 3; maximum head width, dorsally: distance from upper margin of the frons to occipital carina in middle: distance from vertex to clypeal margin in middle $=70: 45: 61$; maximum eye length, laterally: maximum eye width, laterally: maximum eye width, frontal view $=47: 25: 20$; inner-orbital width, 
medially: outer-orbital width, medially: occipital carina width, dorsally $=3: 3: 1$; maximum width of gena, laterally: distance between antennal sockets, frontal view =13: 9; distance between inner margins of hind ocelli: distance between outer margin of hind ocellus and nearest inner eye margin: distance between posterior margin of hind ocellus and occipital carina, dorsally $=6: 14: 19$.

Mesosoma (Fig. 4G, I, K, L). Pronotal collar moderately elevated medially, anterior pronotal ridge strong, lateral angles blunt and not projected (Fig. 4G); width of collar in middle: length of collar in middle $=5: 35$; mesoscutum with fine, sparsed mixed with sparse, coarse punctures, with several, slender, transverse striations anteriorly [striations sometimes lacking] (Fig. 4L), posterior area with sparse, strong parallel ridges (Fig. 4G); admedian line inconspicuous, extending to one third of scutum length; notaulus inconspicuously grooved, extending to one third of scutum length (Fig. 4L); parapsidal line weakly impressed; scutellum with fine, sparse punctures; metanotum with sparse, slender, longitudinal rugae on lateral area, median area smooth (Fig. 4G); mesopleuron with coarse, sparsed punctures, hypoepimeral and posterior area with slender or sturdy, dense, long, longitudinal rugae posteriorly; scrobal suture, omaulus and hypersternaulus broad and distinct, foveolate, scrobal suture short, incomplete (Fig. 4I); propodeal enclosure shallowly impressed, triangular, with sturdy longitudinal rugae, median area reticulate; propodeum posterior with broad shallow median groove, sparse sturdy, oblique, longitudinal rugae anteriorly, large smooth area medially, and irregular reticulation posteriorly (Fig. $4 \mathrm{~K}$ ); propodeum laterally with several, sturdy, oblique, longitudinal rugae anteriorly and medially, and irregular reticulation posteriorly (Fig. 4I).

Metasoma (Fig. 4M-P). Petiole dorsal slightly convex and widened toward apex slightly, with few irregularly weak rugae basally (Fig. $4 \mathrm{~N}$ ), petiole laterally smooth (Fig. 4O); maximum width of petiole, dorsally: length of petiole, laterally: maximum length of metasomal tergum I, dorsally: maximum width of metasomal tergum I, dorsally $=8: 50: 32: 37$; metasomal sterna IV-VI with dense, fine punctures, remainder nearly impunctate (Fig. 4P); pygidial area coriaceous, depressed, u-shaped, apex truncate (Fig. 4M).

Male (Figs 4D, E, H, J, 6E). Similar to female except length of body $5-5.4 \mathrm{~mm}$; labrum and palpi yellowish; tegula dark brown; setae on mandible and margin of clypeus silvery and yellowish, respectively; mandible bidentate apically; labrum subquadrate; clypeus slightly convex, with dense, fine punctures; free margin of clypeus slightly emarginate medially; occipital carina broader than female, distinctly foveolate; length of scape: length of pedicel $=19: 8$; maximum head width, dorsally: distance from upper margin of the frons to occipital carina in middle: distance from vertex to clypeal margin in middle $=65: 40: 53$; maximum eye length, laterally: maximum eye width, laterally: maximum eye width, frontal view $=43: 28: 21$; maximum width of gena, laterally: distance between antennal sockets, frontal view $=11: 7$; distance between inner margins of hind ocelli: distance between outer margin of hind ocellus and nearest inner eye margin: distance between posterior margin of hind ocellus and occipital carina, dorsally $=7: 11: 12$; width of collar in middle: length of collar in middle $=5: 30$; maximum width of petiole, dorsally: length of petiole, laterally: maximum length of metasomal 
tergum I, dorsally: maximum width of metasomal tergum I, dorsally = 7: 50: 28: 27; metasomal sterna III-VI with sparse, fine punctures, remaining nearly impunctate.

Distribution. China (Yunnan).

Etymology. The name, rugipunctatus, is derived from the Latin words ruga (= ruga, wrinkle) and punctum (= puncture), referring to the lower gena with coarse punctures mixed with rugae.

Carinostigmus triangularis Bashir \& Ma, sp. nov.

http://zoobank.org/0E13FFC2-B720-4230-BE94-D5F6881C2A51

Figs 5, 6F

Type material. Holotype: $\bigcirc$, China: Yunnan: Jinghong: Menghai: Bulang Mountain, $21^{\circ} 56^{\prime} \mathrm{N}, 100^{\circ} 26^{\prime} \mathrm{E}, 20 . \mathrm{VI} .2018-20 . V I I .2018$, No. 2019000381, coll. Malaise trap (YNAU); Paratypes: 3의 same locality as holotype, No. 2019000378, 17.V.2018-20. VI.2018, No. 2019000151, 25.IV.2018-17.V.2018, No. 20190329.

Diagnosis. Differs from Chinese species of Carinostigmus by the following features: flagellomeres I-II fulvous; legs largely black; labrum distinctly constricted subapically; free margin of clypeus slightly turnup apically; inter-antennal tubercle longer than midocellus diameter, slightly broadened at apex; lower gena rugose; pronotal collar with transverse striations medially; metanotum with striations medially; petiole dorsal carinate basally and medially; pygidial area elongate. The new species resembles $C$. costatus Krombein 1984, but can be distinguished it by the following characters (characters of C. costatus in brackets): labrum distinctly triangular, broader than C. costatus (labrum pentagonal, narrower than new species); clypeus moderately convex (clypeus slightly convex); median and lower frons with transverse, irregular rugae medially and laterally (median and lower frons without rugae); inter-antennal tubercle longer than midocellus diameter, without T-shape projection (inter-antennal tubercle shorter than midocellus diameter, with T-shape projection); upper frons longitudinal carina without groove before anterior ocellus (upper frons with a weak groove before anterior ocellus); vertex behind ocelli impunctate (vertex behind ocelli punctate); lower gena with dense rugae near midventral line (lower gena without rugae near midventral line); pronotal collar lateral angles projected (pronotal collar lateral angles blunt); notaulus shallowly grooved, extending to one third of scutum length (notaulus deeply grooved, extending to half of scutum length); parapsidal line distinct (parapsidal line weakly impressed); metanotum with transverse striations medially (metanotum without striations medially); propodeal enclosure without triangular impression (propodeal enclosure with triangular impression); propodeum laterally with densely rugose (propodeum laterally sparsely rugose); petiole sub quadrate dorsally (petiole cylindrical) and pygidial area very elongate (pygidial area not elongate as new species).

Description. Female (Figs 5, 6F): length of body 5.5 [5.2-5.7] mm.

Colouration. Body black and shiny, except for the following: mandible ivory to fulvous (black basally and apically); labrum ivory with dark brown sides; palpi, 

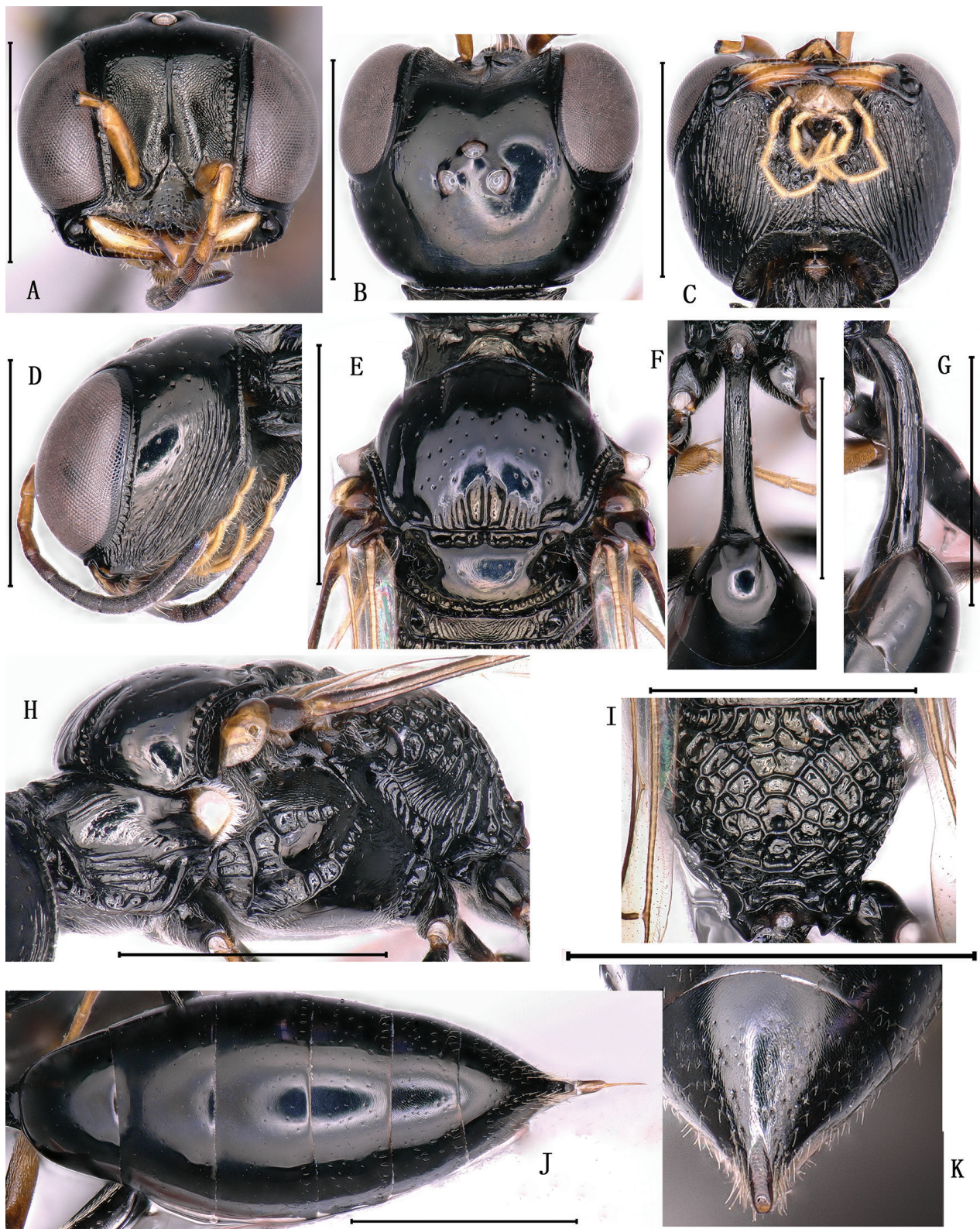

Figure 5. Carinostigmus triangularis Bashir \& Ma, sp. nov. (female) A head, frontal $\mathbf{B}$ head, dorsal $\mathbf{C}$ head, ventral D head, lateral E scutum, scutellum and metanotum, dorsal $\mathbf{F}$ petiole, dorsal $\mathbf{G}$ petiole, lateral $\mathbf{H}$ thorax, lateral I propodeum, dorso-posterior J metasoma, dorsal $\mathbf{K}$ pygidial plate. Scale bars: $1.0 \mathrm{~mm}$.

scape, pedicel and flagellomeres I-II (remainder dark brown) fulvous; pronotal lobe white; tegula and forewing veins dark brown; legs black (fore tibia, fore and mid tarsus fulvous, mid tibia and hind tarsus reddish brown); setae on margin of clypeus and mandible yellowish. 

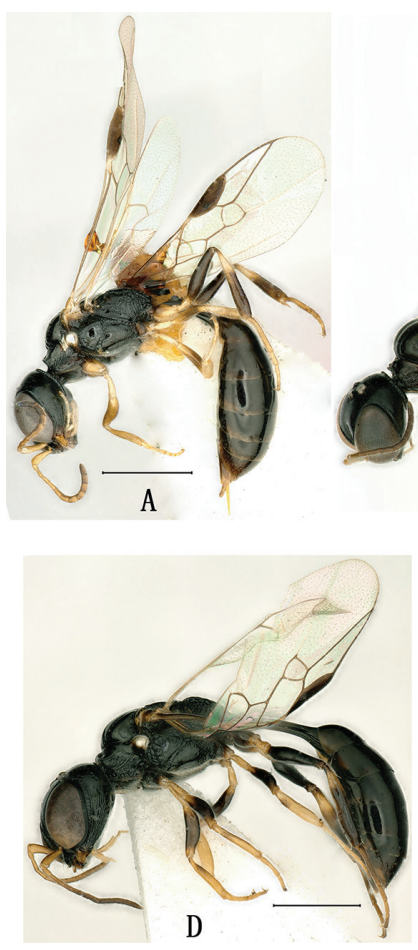
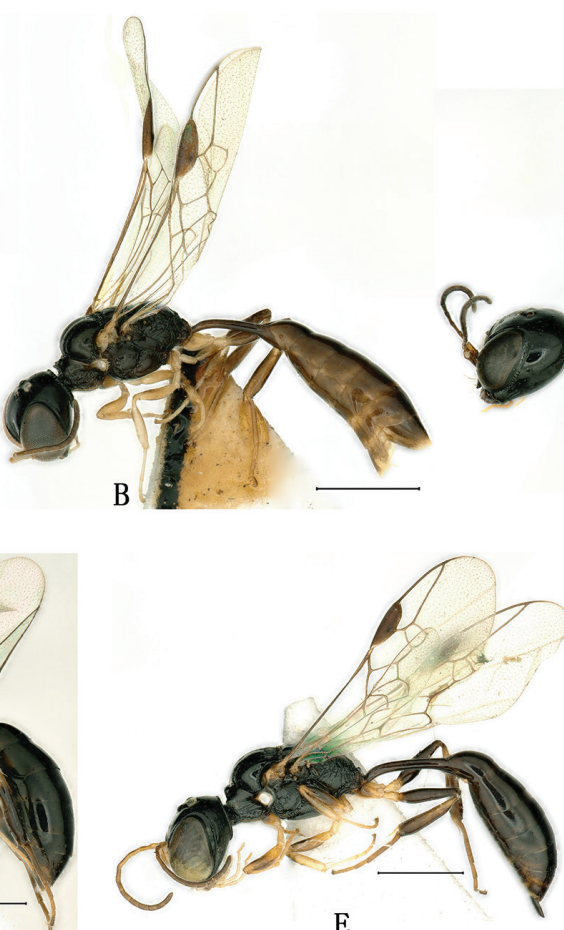

$\mathrm{E}$
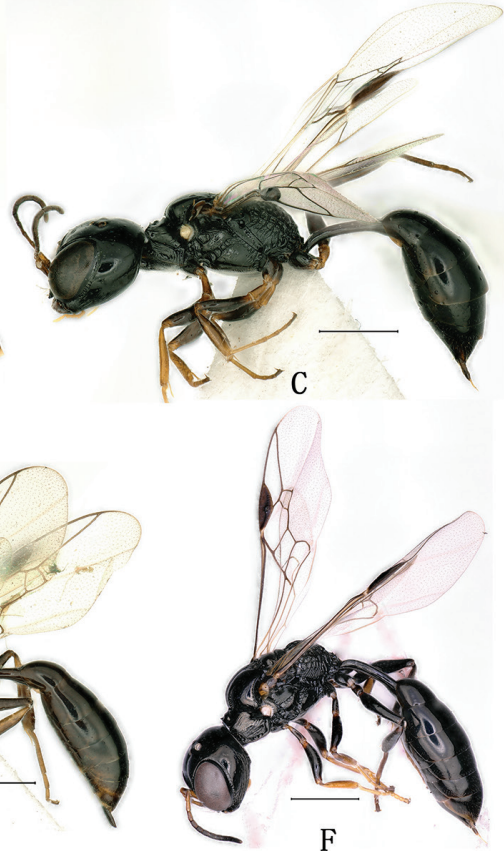

Figure 6. A, B Carinostigmus capiconvergens Bashir \& Ma, sp. nov. (A female B male) C Carinostigmus longivertex Bashir \& Ma sp. nov. (female) D, E Carinostigmus rugipunctatus Bashir \& Ma sp. nov. (D female E male) F Carinostigmus triangularis Bashir \& Ma, sp. nov. (female) A-F lateral view. Scale bars: $1.0 \mathrm{~mm}$.

Head (Fig. 5A-D). Mandible tridentate apically; setae on mandible sparse and long; labrum triangular, round at apex, distinctly constricted subapically; clypeus moderately convex, with sparse, coarse punctures; setae on margin of clypeus sparse and long; free margin of clypeus truncate medially, slightly turnup apically (Fig. 5A); median and lower frons distinctly coriaceous, with transverse, irregular rugae medially and laterally, and with a sturdy frontal median longitudinal carina; inter-antennal tubercle longer than midocellus diameter, slightly broadened at apex; upper frons with sparse, fine punctures, longitudinal carina distinct anteriorly, not reaching anterior ocellus (Fig. 5A); ocellar triangle nearly flat, half mat, with fine, sparse punctures; vertex behind ocelli half mat, nearly impunctate (Fig. 5B); gena with several, sturdy, oblique, transverse rugae medially (Fig. 5D); lower gena with dense, sturdy, regular rugae (Fig. 5C); occipital carina narrow, inconspicuously foveolate (Fig. 5B); inner orbital furrow narrow, with inner marginal carina distinct, inconspicuously foveolate (Fig. 5A); outer orbital furrow narrow, hind marginal carina distinct, inconspicuously foveolate (Fig. 5D); length of scape: length of pedicel: length of flagellomere I: width of flagellomere I = 23: 7: 7: 4; maximum head width, dorsally: distance from upper margin of the frons to occipital carina in middle: distance from vertex to clypeal margin in middle $=75$ : 48: 56 ; maximum 
eye length, laterally: maximum eye width, laterally: maximum eye width, frontal view = 47: 21: 18; inner-orbital width, medially: outer-orbital width, medially: occipital carina width, dorsally $=3: 2: 1$; maximum width of gena, laterally: distance between antennal sockets, frontal view $=28: 14$; distance between inner margins of hind ocelli: distance between outer margin of hind ocellus and nearest inner eye margin: distance between posterior margin of hind ocellus and occipital carina, dorsally $=7: 14: 24$.

Mesosoma (Fig. 5E, H, I). Pronotal collar strongly elevated medially, with transverse striations medially, anterior pronotal ridge strong, lateral angles sharp and projected (Fig. $5 \mathrm{E}$ ); width of collar in middle: length of collar in middle = 11: 36; mesoscutum with coarse punctures, sparsely distributed, posterior area with dense, strong parallel ridges; admedian line weakly impressed, extending to anterior $1 / 4$ of scutum length; notaulus shallowly grooved and foveolate, extending to one third of scutum length; parapsidal line distinct; scutellum with coarse, sparse punctures; metanotum with sparse, sturdy longitudinal rugae laterally, and dense transverse striations medially (Fig. 5E); mesopleuron with fine, sparsed punctures, hypoepimeral area with dense, irregular weak striations, posterior area with contiguous, long rugae; omaulus broadened, $1.2 \times$ pedicel length; hypersternaulus broadened anteriorly, $1.3 \times$ pedicel length, narrow apically, $0.5 \times$ pedicel length, distinctly foveolate; scrobal suture long, complete (Fig. $5 \mathrm{H}$ ); propodeal enclosure deeply impressed, sub triangular, with sturdy, longitudinal rugae anteriorly, reticulate medially; propodeum posterior with sturdy, irregular reticulation (Fig. 5I); propodeum laterally with sparse, sturdy, oblique, longitudinal rugae anteriorly, and irregular reticulation posteriorly (Fig. $5 \mathrm{H}$ ).

Metasoma (Fig. 5F, G, J, K). Petiole dorsal sub quadrate (not cylindrical), carinate basally and medially, basal width of petiole narrower to its apical width (Fig. 5F), petiole laterally with few weak carinae (Fig. 5G); maximum width of petiole, dorsally: length of petiole, laterally: maximum length of metasomal tergum I, dorsally: maximum width of metasomal tergum I, dorsally = 8: 54: 24: 30; metasoma half mat, with fine, sparse punctures (Fig. $5 \mathrm{~J}$ ); pygidial area smooth, very elongate, $1.8 \times$ pedicel length (Fig. $5 \mathrm{~K}$ ).

Male. Unknown

Distribution. China (Yunnan).

Etymology. The name, triangularis, is derived from the Latin word triangulus (= triangle), referring to the triangular shape of the labrum.

\section{Key to the Chinese species of the genus Carinostigmus Tsuneki}

Note: The key is updated from Bashir et al. (2020). Female of C. nozakai Tsuneki, and males of $C$. frontirugatus Bashir \& Ma, C. longivertex sp. nov. and C. triangularis sp. nov. are unknown.

1 Ten flagellomeres; metasoma with six segments (Fig. 5J); mandible tridentate api-

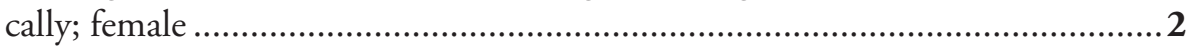

- Eleven flagellomeres; metasoma with seven segments; mandible bidentate apically

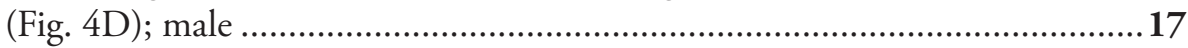

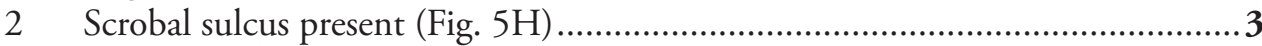

- Scrobal sulcus absent or inconspicuous (Fig. 2I) ............................................11 
3 Propodeal posterior extensively covered by reticulated well-marked ridges (Fig.

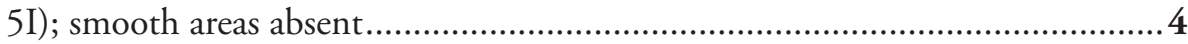

- Propodeal posterior with median groove, several slender or sturdy longitudinal rugae anteriorly; small or large smooth area medially (Fig. 3J) ..........................

4 Frontal line reaching anterior ocellus; petiole smooth dorsally and laterally, without striations (Oriental region)

C. formosanus (Tsuneki)

- Frontal line not reaching anterior ocellus (Fig. 5B); weak transversal or longitudinal striations on petiole dorsal surface (Fig. 5F), few inconspicuous carina or groove on petiole lateral surface (Fig. 5G)

5 Labrum triangular (Fig. 5A); vertex behind ocelli impunctate (Fig. 5B); propodeal enclosure without triangular impression (Fig. 5I); pygidial area very elongate (Fig. 5K) (Oriental region)

C. triangularis sp. nov.

- Labrum pentagonal (Fig. 2A); vertex behind ocelli finely punctate; propodeal enclosure with triangular impression; pygidial area oval or u-shaped ..................6

6 Inter-antennal tubercle long, equal or more than midocellus diameter; gena punctate ventrally; lateral surface of petiole with two distinct lateral carinae; pygidial area oval shaped (Oriental region)

C. maior (Maidl)

- Inter-antennal tubercle shorter than midocellus diameter; gena rugate ventrally; lateral surface of petiole with few weak carinae; pygidial area u-shaped (Oriental region) C. costatus Krombein

7 Free margin of clypeal lobe emarginated .8

- Free margin of clypeal lobe truncate medially.................................................10

8 Free margin of clypeal lobe deeply emarginated (Oriental region) C. palawanensis (Tsuneki)

- Free margin of clypeal lobe slightly emarginated (Figs 3A, 4A). 9

9 Propodeum posteriorly with small smooth area medially (Fig. 3J); petiole laterally with few weak carinae (Fig. 3H); notaulus deeply grooved (Fig. 3F); occipital carina narrow (Fig. 3B); inter-antennal tubercle distinctly broadened at apex, long (Fig. 3B) (Oriental region)

C. longivertex sp. nov.

- Propodeum posteriorly with large smooth area medially (Fig. 4K); petiole laterally without carinae, smooth (Fig. 4O); notaulus inconspicuously grooved (Fig. 4L); occipital carina broad (Fig. 4B); inter-antennal tubercle not broad at apex, short (Fig. 4B) (Oriental region)

C. rugipunctatus sp. nov.

10 Pygidial area punctate throughout; omaulus broadened as midtibial width; lower gena with coarse punctures; clypeus moderately convex; several slender transverse striations anteriorly on scutum (Oriental region).....

C. frontirugatus Bashir \& Ma

- Pygidial area punctate medially; omaulus narrowed; lower gena with fine punctures; clypeus slightly convex; scutum without transverse striations anteriorly (Palearctic and Oriental regions)

C. iwatai (Tsuneki)

11 Posterior surface of propodeum with large smooth area medially; free margin of clypeal lobe nearly truncate or with four teeth medially

- Posterior surface of propodeum without large smooth area medially; free margin of clypeal lobe with three distinct teeth medially....... 
12 Labrum wider than long, sub quadrate; free margin of clypeal lobe with four teeth, median lobe broadly produced, with two small inconspicuous lateral teeth, slightly reflexed apically, lateral lobe with a strong tooth on each side (Oriental region)

C. latidentatus Bashir \& Ma

- Labrum longer than wide, round toward apex; free margin of clypeal lobe truncate, sinuous, not forming reflexed teeth

13 Scutum posterior area with sparse strong parallel ridges (Fig. 2G); ocellar triangle and vertex behind ocelli impunctate (Fig. 2B); outer orbital furrow narrow (Fig. 2F); omaulus and hypersternaulus broadened, distinctly foveolate (Fig. 2I); pygidial area u-shaped (Fig. 2M) (Oriental region) ....... C. capiconvergens sp. nov.

- Scutum posterior area without parallel ridges; ocellar triangle and vertex behind ocelli finely punctate; outer orbital furrow broad; omaulus and hypersternaulus narrowed, not foveolate; pygidial area oval shaped (Oriental region)

C. vesulcatus Bashir \& Ma

14 Inter-antennal tubercle short, less than midocellus diameter ..........................15

- Inter-antennal tubercle long, equal or more than midocellus diameter .............16

15 Upper frons with dense, slender striations, impunctate; vertex impunctate (Palearctic and Oriental regions) ................................ f. filippovi (Gussakovskij)

- Upper frons smooth, without striations, with fine punctures; vertex with sparsed, fine punctures (Palearctic and Oriental regions) ........................ . tanoi Tsuneki

16 Pronotal collar with sparsed, inconspicuous rugae laterally; scutum dull, with fine punctures; notaulus deeply grooved and foveolate, extending to one third of scutum length; inner and outer-orbital sulcus broad; lower gena with coarse punctures; upper frons with several, fine punctures, frontal longitudinal carina distinct, reaching anterior ocellus (Palearctic and Oriental regions) C. kaibuanus Li \& Yang

- Pronotal collar smooth, without rugae laterally; scutum shiny, with coarse punctures; notaulus inconspicuous, extending to anterior $1 / 4$ of scutum length; inner and outerorbital sulcus narrowed; lower gena impunctate; upper frons impunctate, without frontal longitudinal median carina (Oriental region)............... C. saigusai (Tsuneki)

17 Scrobal sulcus well-marked, short or long, distinctly foveolate (Fig. $5 \mathrm{H}$ ) .........18

- Scrobal sulcus absent or very weakly impressed (Fig. 2K) ...............................22

18 Scrobal sulcus long (Fig. 5H); lateral surface of petiole with a groove medially, two distinct lateral carinae or with a groove basally and medially; ocellar triangle area dull, with coarse punctures; free margin of clypeal lobe deeply emarginated medially

- Scrobal sulcus short (Fig. 4J); lateral surface of petiole with a few weak carinae or smooth; ocellar triangle area shiny, with fine punctures; free margin of clypeal lobe slightly emarginated medially

19 Gena punctate ventrally; inter-antennal tubercle long, equal or more than midocellus diameter; admedian line inconspicuous; scutellum median line impressed (Oriental region)

C. maior (Maidl)

- Gena rugate ventrally; inter-antennal tubercle short, less than midocellus diameter; admedian line conspicuous; scutellum median line not impressed (Oriental region) 
20 Petiole dorsal with few irregularly weak rugae basally (Fig. 4N); clypeus with dense, fine punctures (Fig. 4D); inter-antennal tubercle short (Fig. 4E); notaulus inconspicuously grooved (Fig. 4L) (Oriental region) .. C. rugipunctatus sp. nov.

- Petiole dorsal without rugae basally, smooth; clypeus with sparsed, coarse punctures; inter-antennal tubercle long; notaulus deeply grooved

21 Vertex behind ocelli dull, impunctate; gena smooth; occipital carina narrowed; inner and outer-orbital sulcus narrowed; pronotal collar smooth; metanotum smooth; petiole lateral surface smooth (Oriental region)

C. formosanus (Tsuneki)

- Vertex behind ocelli shiny, with fine punctures; gena with several sturdy oblique transverse rugae near mandible area; occipital carina distinctly broad; inner and outer-orbital sulcus broad; pronotal collar with sparsed sturdy rugae; metanotum with dense sturdy longitudinal rugae laterally, smooth medially; petiole lateral with a few weak carinae (Palearctic and Oriental regions)

C. iwatai (Tsuneki)

22 Extensive smooth area present on posterior surface of propodeum mesally; free margin of clypeal lobe with two triangular lateral teeth

- Extensive smooth area absent on posterior surface of propodeum mesally; free margin of clypeal lobe with three distinct teeth

23 Labrum wider than long; lower gena with fine punctures medially; parapsidal line conspicuous (Oriental region)

C. latidentatus Bashir \& Ma

- Labrum longer than wide; lower gena with weak striations or rugulose medially; parapsidal line inconspicuous.

24 Ocellar triangle and vertex behind ocelli impunctate (Fig. 2E); outer orbital furrow narrow (Fig. 2F); omaulus and hypersternaulus broad, distinctly foveolate (Fig. 2K); pronotal collar lateral angles sharp and projected (Fig. 2J); notaulus inconspicuous (Fig. 2L) (Oriental region)

C. capiconvergens sp. nov.

- Ocellar triangle and vertex behind ocelli finely punctate; outer orbital furrow broad; omaulus and hypersternaulus narrowed, not foveolate; pronotal collar lateral angles blunt and not projected; notaulus deeply grooved (Oriental region)...

C. vesulcatus Bashir \& Ma

25 Inter-antennal tubercle long, equal or more than midocellus diameter; upper frons frontal carina distinct, not reaching anterior ocellus; inner-orbital sulcus broad (Palearctic and Oriental regions)

C. kaibuanus Li \& Yang

- Inter-antennal tubercle short, less than midocellus diameter; upper frons without frontal carina, or if present, clearly reaching anterior ocellus; inner-orbital sulcus narrowed)

26 Upper frons with dense, slender striations; vertex impunctate; upper frons frontal longitudinal carina distinct anteriorly, reaching anterior ocellus (Palearctic and Oriental regions) C. filippovi (Gussakovskij)

- Upper frons without striations; vertex with sparsed fine punctures; frontal carina absent on upper frons.

27 Labrum pentagonal, deeply notched at apex; ocellar triangle with fine, sparsed punctures; lower gena with weak striations; occipital carina narrowed; scutum 
with coarsely punctuated; admedian line inconspicuous; parapsidal line conspicuous (Palearctic and Oriental regions) ....................................... tanoi Tsuneki

- Labrum rounded, without emargination; ocellar triangle impunctate; lower gena smooth; occipital carina broad; scutum with fine punctures; admedian line conspicuous; parapsidal line inconspicuous (Oriental region) ...... . nozakai Tsuneki

\section{Discussion}

Tsuneki (1954) was the first to describe Carinostigmus species from China: C. formosanus and C. iwatai, collected from Taiwan and Hainan, respectively. Later on, several Chinese species were discovered: C. nozakai and C. tanoi from Taiwan (Tsuneki, 1977), and C. kaihuanus from Zhejiang province (Li \& Yang, 1995). Previous faunistic studies conducted on Carinostigmus from China revealed thirteen species (Fig. 1). In this study, four further species: C. capiconvergens (Hainan and Yunnan), C. longivertex (Yunnan), C. rugipunctatus (Yunnan), and C. triangularis (Yunnan) are added to the list. The Chinese territory is placed in between two zoogeographical zones, Oriental and Palearctic. Some species of Carinostigmus are present in both zones. Most of the species are mainly Oriental (C. costatus, C. filippovi, C. frontirugatus, C. latidentatus, C. formosanus, C. maior, C. nozakai, C. palawanensis, C. saigusai, and C. vesulcatus). However, C. iwatai, C. kaihuanus, and C. tanoi are present in both the Palearctic and the Oriental China.

In China, the distribution of Carinostigmus species ranges from Shaanxi province (elevation of 400-600 m) to Taiwan and Hainan (elevation of 900-955 m). More species have been recorded from Yunnan province, followed by Taiwan, Guizhou, Hainan, Guangdong, Fujian, Guangxi, Zhejiang, Sichuan, Shaanxi, Henan, and Hunan. Carinostigmus was found in the south and southwest of China, where the average annual temperature and precipitation is $12-25^{\circ} \mathrm{C}$ and $800-2300 \mathrm{~mm}$.

However, the Chinese fauna of the genus Carinostigmus needs further study. Further research is needed to accurately assess distribution patterns of apoid wasps in China and their biology. In particular, taxonomic studies of Oriental China promise to find new, undiscovered species and new country records in Carinostigmus.

\section{Acknowledgements}

This study was supported by National Natural Science Foundation of China (31760641, 31750002). The authors would like to thank Professor WJ Pulawski for providing literature.

\section{References}

Bashir NH, Ma L, Li Q (2020) Chinese species of Carinostigmus Tsuneki (Hymenoptera, Crabronidae), including three new species and a new record to China. ZooKeys 987: 115-134. https://doi.org/10.3897/zookeys.987.55317 
Bohart RM, Menke AS (1976) Sphecid wasps of the world, a generic revision. University of California Press, Berkeley, Los Angeles, London, 695 pp.

Gussakovskij VV (1934) Beitrag zur Kenntnis der Pseninen-und Pemphredoninen-Fauna Japans (Hymenoptera, Sphecidae). Mushi 7: 79-89.

Harris RA (1979) A glossary of surface sculpturing. Occasional Papers in Entomology 28: 1-31.

Krombein KV (1984) Biosystematic studies of Ceylonese wasps, XIV: a revision of Carinostigmus Tsuneki (Hymenoptera: Sphecoidea: Pemphredonidae). Smithsonian Contributions to Zoology 396: 1-37. https://doi.org/10.5479/si.00810282.396

Li Q, He J (2004) Superfamily Sphecoidea. In: He J (Ed.) Hymenopteran Insect Fauna of Zhejiang. Science Press, Beijing, 1071-1210.

Li Q, Yang C (1995) Hymenoptera: Sphecoidea. In: Zhu T (Ed.) Insects and Macrofungi of Gutianshan, Zhejiang. Science Technique Press of Zhejiang, 270-273.

Ma L, Chen XX, Qiang L (2012) The genus Carinostigmus Tsuneki (Hymenoptera: Crabronidae) with two newly recorded species from China. Entomotaxonomia 34(2): 475-481.

Ma L, Li Q, Wang CH, Jiang X, Lu HX (2018) X Sphecoidea. In: Xuexin C (Ed.) Insect fauna of the Qinling Mountains Hymenoptera. World Book Publishing House Xi'an Co., Ltd., Xi'an, 823-861.

Maidl F (1925) Fauna sumatrensis. (Beitrag Nr. 11). Sphegidae (Hym.). Entomologische Mitteilungen 14: 376-390.

Panzer GWF (1804) Faunae insectorum germanicae initiae oder Deutschlands Insecten. Felseckersche Buchhandlung, Nürnberg, Heft 86, 24 plates.

Pulawski WJ (2020) Carinostigmus: Catalog of Sphecidae. http://researcharchive.calacademy. org/research/entomology/entomology_resources/hymenoptera/sphecidae/genera/Carinostigmus.pdf [accessed 20 November 2020]

Rajan T, Sureshan P, Kumar PG (2020) Additions to the knowledge on the genus Carinostigmus Tsuneki (Hymenoptera: Crabronidae: Pemphredoninae) from the Indian subcontinent with the description of two new species. Zootaxa 4881(1): 152-164. https://doi. org/10.11646/zootaxa.4881.1.9

Tsuneki K (1954) The genus Stigmus Panzer of Europe and Asia, with description of eight new species (Hymenoptera, Sphecidae). Memoirs of the Faculty of Liberal Arts, Fukui University. Series II, Natural Science 3: 1-38.

Tsuneki K (1956) A new species of Stigmus from Morocco (Hymen., Sphecidae, Pemphredoninae). Entomologische Berichten 16: 263-264.

Tsuneki K (1966) Contribution to the knowledge of the Pemphredoninae fauna of Formosa and the Ryukyus (Hymenoptera, Sphecidae). Etizenia 14: 1-21.

Tsuneki K (1974) A contribution to the knowledge of Sphecidae occurring in southeast Asia (Hym.). Polskie Pismo Entomologiczne 44: 585-660.

Tsuneki K (1976) Sphecoidea taken by the Noona Dan expedition in the Philippine Islands (Insecta, Hymenoptera). Steenstrupia 4: 33-120.

Tsuneki K (1977) Further notes and descriptions on some Formosan Sphecidae (Hymenoptera). Special Publications of the Japan Hymenopterists Association 2: 1-32.

Walker F (1860) Characters of some apparently undescribed Ceylon insects. The Annals and Magazine of Natural History (Third Series) 5: 304-311. https://doi. org/10.1080/00222936008697221 